Simultaneous measurement of folate cycle intermediates in different biological matrices using liquid chromatography-tandem mass spectrometry

Nandania, Jatin

2018-08-15

Nandania , J , Kokkonen, M , Euro , L \& Velagapudi , V 2018 , ' Simultaneous measurement of folate cycle intermediates in different biological matrices using liquid chromatography-tandem mass spectrometry ', Journal of Chromatography. B, vol. 1092 , pp. 168-178 . https://doi.org/10.1016/j.jchromb.2018.06.008

http://hdl.handle.net/10138/304167

https://doi.org/10.1016/j.jchromb.2018.06.008

publishedVersion

Downloaded from Helda, University of Helsinki institutional repository.

This is an electronic reprint of the original article.

This reprint may differ from the original in pagination and typographic detail.

Please cite the original version. 


\title{
Simultaneous measurement of folate cycle intermediates in different biological matrices using liquid chromatography-tandem mass spectrometry
}

\author{
Jatin Nandania $^{\mathrm{a}, 1}$, Meri Kokkonen ${ }^{\mathrm{a}, 2}$, Liliya Euro ${ }^{\mathrm{b}, *}$, Vidya Velagapudi ${ }^{\mathrm{a}, * *}$ \\ a Metabolomics Unit, Institute for Molecular Medicine Finland (FIMM), HiLIFE, University of Helsinki, Tukholmankatu 8, Biomedicum 2U, 00290 Helsinki, Finland \\ ${ }^{\mathrm{b}}$ Research Programmes Unit, Molecular Neurology, Biomedicum 1, University of Helsinki, 00290 Helsinki, Finland
}

\section{A R T I C L E I N F O}

\section{Keywords:}

Folate cycle metabolites

Mass spectrometry

Chromatography

biological matrices

analytical method

validation

\begin{abstract}
A B S T R A C T
The folate cycle is an essential metabolic pathway in the cell, involved in nucleotide synthesis, maintenance of the redox balance in the cell, methionine metabolism and re-methylation reactions. Standardised methods for the measurement of folate cycle intermediates in different biological matrices are in great demand. Here we describe a rapid, sensitive, precise and accurate liquid chromatographic-tandem mass spectrometric (LC-MS/ MS) method with a wide calibration curve range and a short run time for the simultaneous determination of folate cycle metabolites, including tetrahydrofolic acid (THF), 5-methyl THF, 5-formyl THF, 5,10-methenyl THF, 5,10-methylene THF, dihydrofolic acid (DHF) and folic acid in different biological matrices. Extraction of folate derivatives from soft and hard tissue samples as well as from adherent cells was achieved using homogenisation in buffer, while extraction from the whole blood and plasma relied on the anion exchange solid-phase extraction (SPE) method. Chromatographic separation was completed using a Waters Atlantis $\mathrm{dC}_{18} 2.0 \times 100 \mathrm{~mm}, 3-\mu$ column with a gradient elution using formic acid in water $(0.1 \% \mathrm{v} / \mathrm{v})$ and acetonitrile as the mobile phases. LC gradient started with $95 \%$ of the aqueous phase which was gradually changed to $95 \%$ of the organic phase during $2.70 \mathrm{~min}$ in order to separate the selected metabolites. The analytes were separated with a run time of $5 \mathrm{~min}$ at a flow rate of $0.300 \mathrm{~mL} / \mathrm{min}$ and detected using a Waters Xevo-TQS triple quadrupole mass spectrometer in the multiple reaction monitoring mode (MRM) at positive polarity. The instrument response was linear over a calibration range of 0.5 to $2500 \mathrm{ng} / \mathrm{mL}\left(\mathrm{r}^{2}>0.980\right)$. The developed bioanalytical method was thoroughly validated in terms of accuracy, precision, linearity, recovery, sensitivity and stability for tissue and blood samples. The matrix effect was compensated by using structurally similar isotope labelled internal standard (IS), ${ }^{13} \mathrm{C}_{5}$-methyl THF, for all folate metabolites. However, not all folate metabolites can be accurately quantified using this method due to their high interconversion rates especially at low $\mathrm{pH}$. This applies to 5,10-methylene THF which interconverts into THF, and 5,10-methenyl-THF interconverting into 5-formyl-THF. Using this method, we measured folate cycle intermediates in mouse bone marrow cells and plasma, in human whole blood; in mouse muscle, liver, heart and brain samples.
\end{abstract}

\section{Introduction}

Folic acid, or vitamin $\mathrm{B}_{9}$, is a water-soluble compound essential for normal tissue growth and development [1]. It consists of a pteridine ring, $p$-aminobenzoate and a glutamyl moiety. Animal cells are not able to synthesise folic acid; therefore, diet and microbiota are the sources of this vitamin. After being transported into the cell, folic acid undergoes poly- $\gamma$-glutamylation to retain within the cell, followed by stepwise reduction by dihydrofolate reductase using NADPH to its active form of tetrahydrofolate (THF), which can carry a one-carbon unit conjugated to nitrogen at position 5 or 10 in the pteridine ring [2,3]. The most common one-carbon donor for THF is serine [4]. THF with a bound carbon unit can exist in several intermediates distinguished by different oxidation states of the shuttled carbon. The transformation of one form of THF to the other takes place during the folate cycle. Each THF intermediate fuels a certain metabolic pathway linked to the folate cycle. As such, 5-methyl THF donates the methyl group for methionine regeneration in the methionine cycle and, therefore, for all re-methylation reactions in the cell; 5,10-methylene THF is used in thymidylate synthesis; and 10-formyl THF is the source of formate and substrate in

\footnotetext{
* Corresponding author.

** Corresponding author at: Institute for Molecular Medicine Finland (FIMM), Tukholmankatu, Biomedicum 2U, HiLIFE, University of Helsinki, Helsinki 00290, Finland.

E-mail addresses: Liliya.Euro@helsinki.fi (L. Euro), vidya.velagapudi@helsinki.fi (V. Velagapudi).

${ }^{1}$ Present address: Roche Diagnostics GmbH, Nonnenwald 2, 82377 Penzberg, Germany.

${ }^{2}$ Present address: Finnish Customs Laboratory, Tekniikantie 13, 02150 Espoo, Finland.
} 
<smiles>Nc1nc2ncc(CNc3ccc(C(=O)NC(CCC(=O)O)C(=O)O)cc3)nc2c(=O)[nH]1</smiles><smiles>Nc1nc(=O)c2c([nH]1)NC[C@@H](CNc1ccc(C(=O)N[C@@H](CCC(=O)O)C(=O)O)cc1)N2</smiles>

Tetrahydrofolate (THF)<smiles>Nc1nc(=O)c2c([nH]1)NCC1CN(c3ccc(C(=O)NC(CCC(=O)O)C(=O)O)cc3)CC21</smiles>

5,10-Methylene THF<smiles>Nc1nc(=O)c2c([nH]1)NCC1CN(c3ccc(C(=O)NC(CCC(=O)O)C(=O)O)cc3)CN21</smiles>

5,10-Methenyl THF<smiles>Nc1nc(=O)c2c([nH]1)NCC(CNc1ccc(C(=O)N[C@@H](CCC(=O)O)C(=O)O)cc1)N2C=O</smiles>

5-Formyl THF<smiles>CN1c2c([nH]c(=N)[nH]c2=O)NCC1CNc1ccc(C(=O)NC(CCC(=O)[O-])C(=O)[O-])cc1</smiles>

5-Methyl THF

Fig. 1. Chemical structures of the folate metabolites.

purine synthesis [5]. Chemical structures of the folate metabolites are shown in Fig. 1. The oxidation of a shuttled carbon atom in the folate cycle is accompanied by the production of NADPH, critical for defence against oxidative stress and reductive biosynthesis in the cell [6]. The folate cycle is especially important for highly proliferative cells [7]. However, not much is known about the tissue- and condition-specific modulation of the folate cycle, including whether all THF intermediates are present in equal amounts or the production of one form of THF can overweigh production of the others. Progress in this area is hampered by the absence of a sensitive quantitative method for the simultaneous measurement of all THF intermediates from a single biological sample. The main challenges in the analysis of these compounds are their instability, pH-dependent interconversion and the varying length of the poly- $\gamma$-glutamyl tail. Furthermore, endogenous folate metabolites are present in very low amounts within biological matrices. Although a number of publications described analytical methods for the determination of selected folate cycle metabolites [8-13], there is no standardised method which could be used for the simultaneous determination of all THF derivatives in different biological matrices. For instance, Jia et al. quantitatively measured all folate metabolites except 5,10-methylene THF from human colonic mucosa samples using labelled isotope compounds as the internal standard [9]. In addition, Odin et al. measured 5,10-methylene THF and 5-methyl THF from colorectal mucosa and tumour tissues [10]. Fazili et al. quantitatively determined folate metabolites such as folic acid, 5-methyl THF and 5-formyl THF from blood and serum samples using a solid-phase extraction technique $[11,12]$. By contrast, Filip et al. analysed free and total folate in plasma and red blood cells using a stable isotope dilution liquid chromatographic-tandem mass spectrometric (LC-MS/MS) method in clinical samples [13].

The primary objective of the present work, therefore, was to develop a rapid, simple, accurate, precise and sensitive method for the measurement of core folate cycle metabolites-folic acid, tetrahydrofolic acid, 5,10-methenyl THF, 5,10-methylene THF, 5-formyl THF, 5-methyl THF and dihydrofolic acid-from different biological matrices. To do so, we used tandem mass spectrometry, which emerged as an established analytical technique for the analysis of metabolites from complex biological samples. The key advantages of the LC-MS/MS technology include its ability to accurately identify and quantify several coenzyme species simultaneously.

\section{Materials and methods}

\subsection{Chemicals, reagents and samples}

Folate metabolites, including folic acid (purity $>98.5 \%$ ), tetrahydrofolic acid (purity 95-98\%), 5-methyl THF (purity > 95\%), 5-formyl THF (purity > 99\%), 5,10-methenyl THF (purity $>97.5 \%$ ), 5,10-methylene THF (purity > 93\%), dihydrofolic acid (purity 90-95\%) and labelled internal standard ${ }^{13} \mathrm{C}_{5}$-methyl THF, were purchased from Schricks Laboratory (Jona, Switzerland). LC-MS grade acetonitrile and methanol (HiPerSolv) were obtained from VWR International (Helsinki, Finland). Other chemicals, such as formic acid, $\beta$-mercaptoethanol, ascorbic acid, potassium hydroxide and a HEPES buffer, were of high-grade purity and purchased from Sigma Aldrich (St. Louis, MO, USA). Deionised water $\left(18 \mathrm{M} \Omega \cdot \mathrm{cm}\right.$ at $\left.25^{\circ} \mathrm{C}\right)$ used for solution preparation was made using a Milli-Q water purification system procured from Merck Millipore (Billerica, MA, USA). Rat plasma with heparin as the anticoagulant was purchased from Innovative Research Laboratory (Novi, MI, USA). Whole human blood was procured from the Finnish Red Cross blood service (Helsinki, Finland). Mouse heart, liver, brain and muscle tissue samples from CD5 mice 7- to 12-weeks old maintained on standard small rodent chow, were obtained from Innovative Research Laboratory (Novi, MI, USA). Finally, mouse bone marrow and mouse plasma samples were kindly donated by Professor Anu Wartiovaara's laboratory (Biomedicum, University of Helsinki, Finland). Each bone marrow sample was obtained from two femur bones from a single animal. All biological samples were stored at $-80^{\circ} \mathrm{C}$ until used. 


\subsection{Solution preparation}

HEPES buffer with pH 8.0 was used to prepare stock solutions and working solutions to prevent degradation of folate metabolites and to maintain optimal conditions for deconjugase enzyme activity [9]. Stock solutions for each metabolite were prepared at a final concentration of $0.5 \mathrm{mg} / \mathrm{mL}$ in a HEPES buffer at pH 8.0 (50 mM HEPES buffer containing $1 \%$ ascorbic acid $(\mathrm{w} / \mathrm{v})$ and $1 \% \beta$-mercaptoethanol $(\mathrm{v} / \mathrm{v})$, adjusted to $\mathrm{pH} 8.0$ with potassium hydroxide). A working solution containing all metabolites with a $5000 \mathrm{ng} / \mathrm{mL}$ concentration for each was prepared in a HEPES buffer ( $\mathrm{pH}$ 8.0). Calibration curve solutions were prepared by serial dilution from the working solution in a HEPES buffer ( $\mathrm{pH} 8.0$ ) to yield a concentration range of 0.5 to $2500 \mathrm{ng} / \mathrm{mL}$. An internal standard $\left({ }^{13} \mathrm{C}_{5}\right.$-methyl THF) dilution solution $(400 \mathrm{ng} / \mathrm{mL})$ was prepared from its stock solution $(0.5 \mathrm{mg} / \mathrm{mL})$ in a HEPES buffer (pH 8.0). All standard solutions were stored at $-20^{\circ} \mathrm{C}$ and were protected from light during use and storage. We found these solutions to be stable and used them for method development and validation. An elution solution was prepared by mixing seven parts $1 \% \mathrm{v} / \mathrm{v}$ formic acid and three parts of an acetonitrile/methanol $(1 / 1, \mathrm{v} / \mathrm{v})$ mixture, then adjusting the solution to $\mathrm{pH}$ 5.0. A HEPES buffer at $\mathrm{pH} 8.0$ and a HEPES buffer at $\mathrm{pH}$ 5.0, respectively, were used as the extraction buffer for the tissue and whole blood extraction protocol.

\subsection{Preparation of folate deconjugase}

Folate-free rat plasma was used as a source of pteroylpoly- $\gamma$-glutamate hydrolase for the deconjugation of the polyglutamate tail from THF derivatives to convert them to the monoglytamate forms [10]. We added $750 \mathrm{mg}$ charcoal to $15 \mathrm{~mL}$ rat plasma followed by incubation with mixing for $1 \mathrm{~h}$, at room temperature (RT) and centrifugation at $14,000 \mathrm{rpm}$ for $20 \mathrm{~min}$. Treated rat plasma was filtered through a $0.2-\mu \mathrm{m}$ GHP membrane filter (Pall life sciences, Washington, NY, USA). After that rat plasma was tested to make sure it is free of folate, aliquots were made and stored at $-20 \pm 5^{\circ} \mathrm{C}$ until used.

\subsubsection{Extraction protocol for tissue samples and adherent cells}

An aliquot of $40 \mathrm{mg}$ frozen tissue was transferred to homogenisation tubes (Bertin Technologies, France) with 1.4-mm ceramic (zirconium oxide) beads. A total of $20 \mu \mathrm{L}$ of an internal standard dilution solution ( $400 \mathrm{ng} / \mathrm{mL}$ ) was added and the samples were equilibrated on ice for 2 min. Next, $450 \mu \mathrm{L}$ of an extraction buffer (HEPES buffer $\mathrm{pH} 8.0$ ) was added to the homogenisation tubes and the samples were vortexed for 20 s. Tissue samples were homogenised using a tissue homogeniser (Bertin Technologies, France) over three cycles of $30 \mathrm{~s}$ at $5500 \mathrm{rpm}$ each with a 10-s pause interval between cycles. After homogenisation, $40 \mu \mathrm{L}$ of charcoal-treated rat plasma was added and samples were incubated at $37^{\circ} \mathrm{C}$ for $3 \mathrm{~h}$ for folate deconjugation followed by centrifugation at $14,000 \mathrm{rpm}$ for $15 \mathrm{~min}$ at $4^{\circ} \mathrm{C}$. After centrifugation, $300 \mu \mathrm{L}$ of supernatant was passed through a $10-\mathrm{kDa}$ cut-off filter (Sartorius Stedim Biotech, Germany) at $14,000 \mathrm{rpm}$ for $30 \mathrm{~min}$ at $4{ }^{\circ} \mathrm{C}$, and the filtrate was collected for injection into the chromatographic system for folate analysis.
The same protocol was used for the extraction of folate derivatives from adherent cell pellets (approximately 1 million cells). However, instead of homogenisation, samples were sonicated and vortexed for $30 \mathrm{~s}$ over three cycles to break apart the cell pellets after the addition of internal standards (IS) and a HEPES buffer at pH 8.0.

\subsubsection{Extraction protocol for whole blood}

The tissue sample preparation protocol was ineffective for the whole blood and plasma samples due to the low recovery of folates. We, therefore, used an ion-exchange solid-phase extraction (SPE) to extract folate derivatives from these sample matrices. First, $20 \mu \mathrm{L}$ of an internal standard solution $(400 \mathrm{ng} / \mathrm{mL})$ was added to $40 \mu \mathrm{L}$ of whole blood, vortexed for $20 \mathrm{~s}$ and equilibrated for $2 \mathrm{~min}$ on ice. Next, $850 \mu \mathrm{L}$ of a HEPES buffer (pH 5.0) (prepared as in Section 2.2, pH adjusted with potassium hydroxide) was added as the extraction buffer followed by the addition of $40 \mu \mathrm{L}$ of charcoal-treated rat plasma. Samples were then incubated at $37^{\circ} \mathrm{C}$ for $3 \mathrm{~h}$ for folate deconjugation. The samples were purified using strong anion exchange cartridges (StrataX-A) in a 96-well format with a $30-\mathrm{mg} / \mathrm{mL}$ sorbent mass (Phenomenex, Torrance, CA, USA). Conditioning of SPE cartridges was completed using $1 \mathrm{~mL}$ methanol followed by equilibration with $1 \mathrm{~mL}$ of $1 \% \mathrm{v} / \mathrm{v}$ formic acid in water containing $1 \%(\mathrm{w} / \mathrm{v})$ ascorbic acid. Samples were loaded on SPE cartridges. Then, SPE cartridges were washed twice with $1 \mathrm{~mL}$ of $1 \%$ ascorbic acid (w/v) followed by drying of the SPE cartridges under a vacuum. Finally, samples were eluted with $0.5 \mathrm{~mL}$ of an elution solution and injected into the chromatographic system for folate analysis.

\subsection{Instrument and analytical conditions}

The final analysis of the folates was performed on a UHPLC-MS/MS system consisting of a Waters Acquity UHPLC coupled to a Xevo-TQS triple quadrupole mass spectrometer equipped with an electrospray ionisation probe (Waters Corporation, Milford, MA, USA). Chromatographic separation was completed using an Atlantis dC18 reversed-phase analytical column $(2.0 \times 100 \mathrm{~mm}, 3-\mu$ particles $)$ from Waters (Milford, MA, USA). Gradient elution with a flow rate of $0.300 \mathrm{~mL} / \mathrm{min}$ was carried out using $0.1 \%$ formic acid in water $(\mathrm{v} / \mathrm{v})$ as mobile phase A and acetonitrile as mobile phase B. The elution was initiated with an isocratic step of $95 \%$ of mobile phase A maintained until $0.33 \mathrm{~min}$ and then gradually increasing the proportion of mobile phase B to $95 \%$ over the next $2.70 \mathrm{~min}$. Next, the mobile phase was immediately adjusted to its initial composition during the next $2.30 \mathrm{~min}$, with a total analysis time for a single injection of $5 \mathrm{~min}$. The column oven and auto-sampler temperatures were set to $40 \pm 3{ }^{\circ} \mathrm{C}$ and $5 \pm 3{ }^{\circ} \mathrm{C}$, respectively. We used an injection volume of $5 \mu \mathrm{L}$ for the sample extract. The auto-sampler was used to perform a partial loop with a needle overfill injection for samples and standards. Positive electrospray ionisation was used for the detection of folate metabolites. The protonated molecular ions $[\mathrm{M}+\mathrm{H}]^{+}$of the folates were selected as the precursor ions, since these produced the highest response during optimisation of the instrument parameters. One specific mass transition $(\mathrm{m} / \mathrm{z})$ was chosen for each compound using the multiple reaction monitoring mode (MRM) function of the instrument for quantitation.

Table 1

Chemical formula and mass-dependent parameters for folate metabolites.

\begin{tabular}{|c|c|c|c|c|c|}
\hline Compound name & Chemical formula & Mass transition (quantifier) & Mass transition (qualifier) & Cone voltage $(\mathrm{eV})$ & Collision voltage (V) \\
\hline Folic acid & $\mathrm{C}_{19} \mathrm{H}_{19} \mathrm{~N}_{7} \mathrm{O}_{6}$ & $442.20 \rightarrow 176.10$ & $442.20 \rightarrow 295.10$ & 22 & 36 \\
\hline Tetrahydrofolic acid (THF) & $\mathrm{C}_{19} \mathrm{H}_{23} \mathrm{~N}_{7} \mathrm{O}_{6}$ & $446.20 \rightarrow 299.20$ & $446.20 \rightarrow 120.02$ & 26 & 18 \\
\hline 5,10-Methylene THF & $\mathrm{C}_{20} \mathrm{H}_{23} \mathrm{~N}_{7} \mathrm{O}_{6}$ & $458.20 \rightarrow 311.20$ & $458.20 \rightarrow 166.10$ & 24 & 18 \\
\hline 5,10-Methenyl THF & $\mathrm{C}_{20} \mathrm{H}_{20} \mathrm{~N}_{7} \mathrm{O}_{6}$ & $456.00 \rightarrow 412.00$ & $456.00 \rightarrow 282.15$ & 18 & 30 \\
\hline 5-Formyl THF & $\mathrm{C}_{20} \mathrm{H}_{23} \mathrm{~N}_{7} \mathrm{O}_{7}$ & $474.20 \rightarrow 327.20$ & $474.20 \rightarrow 299.20$ & 30 & 18 \\
\hline 5-Methyl THF & $\mathrm{C}_{20} \mathrm{H}_{25} \mathrm{~N}_{7} \mathrm{O}_{6}$ & $460.20 \rightarrow 313.20$ & $460.20 \rightarrow 180.10$ & 40 & 18 \\
\hline Dihydrofolic acid & $\mathrm{C}_{19} \mathrm{H}_{21} \mathrm{~N}_{7} \mathrm{O}_{6}$ & $444.00 \rightarrow 178.00$ & $444.00 \rightarrow 136.00$ & 60 & 30 \\
\hline${ }^{13} \mathrm{C}_{5}$-Methyl THF & $\mathrm{C}_{15}{ }^{13} \mathrm{C}_{5} \mathrm{H}_{23} \mathrm{~N}_{7} \mathrm{O}_{6}$ & $465.20 \rightarrow 313.20$ & - & 40 & 18 \\
\hline
\end{tabular}


The optimised compound-dependent mass parameters (i.e., cone voltage and collision energy) and the MRM transitions are listed in Table 1. The optimised source-dependent parameters, such as capillary voltage, desolvation temperature, desolvation gas flow, cone gas flow and collision gas flow, were maintained constantly at $2.92 \mathrm{kV}, 500{ }^{\circ} \mathrm{C}, 600 \mathrm{~L} / \mathrm{h}$, $150 \mathrm{~L} / \mathrm{h}$ and $0.15 \mathrm{~mL} / \mathrm{min}$, respectively, throughout analysis. Highpurity nitrogen (purity $>99.9 \%$ ) and argon (purity 99.998\%) were used as the desolvation and collision gases, respectively. The MRM acquisition mode was selected for the quantification of metabolites with an individual span time of $0.1 \mathrm{~s}$ provided in their individual MRM channels. The dwell time was calculated automatically based on the region of the retention time window, the number of MRM functions and the number of data points required forming a peak. We used Mass Lynx 4.1 software for instrument control and data acquisition. Quantification of the analytes was completed using the peak area ratio (area of metabolite/area of IS) and a linear least-squares regression curve with a weighting factor of $1 / \mathrm{x}^{2}$.

\subsection{Validation}

The developed method was validated according to the European Medicines Agency (EMA) guidelines for bioanalytical method validation in terms of linearity, precision, accuracy, limit of detection (LOD), limit of quantification (LOQ), recovery, matrix effect and stability [14]. The homogenisation and SPE protocols were followed separately to prepare all tissue samples and whole blood samples, respectively, for each precision and accuracy batch, and for other experiments during method validation. Quality control (QC) samples at high (HQC, $800 \mathrm{ng}$ / $\mathrm{mL}$ ), middle (MQC, $400 \mathrm{ng} / \mathrm{mL}$ ) and low (LQC, $1.0 \mathrm{ng} / \mathrm{mL}$ ) concentration levels were prepared by spiking the standard solution in the respective homogenised biological matrices to complete all method validation experiments. Nevertheless, these matrices contain naturally occurring endogenous folates and, thus, the concentration of the nonspiked samples was always subtracted from the concentration of the spiked samples. Complete validation was performed for the muscle tissue and whole blood samples. Likewise, partial validation, including inter- and intra-day precision, accuracy and recovery, was completed for other tissue types (liver, heart and brain) and adherent cell samples to check method performance. An aqueous calibration curve was used to calculate the concentration values during method validation. A system suitability experiment was performed by injecting six consecutive injections of level 5 with a concentration of $10 \mathrm{ng} / \mathrm{mL}$ at the start of method validation to check instrument performance and response reproducibility in terms of the peak area for each folate metabolite. We observed a \% coefficient of variation (CV) for the system suitability within the range of $0.60 \%$ to $2.17 \%$.

\subsubsection{Auto-sampler carryover}

An auto-sampler carryover experiment was performed at the start of method validation to check the carryover of the highest standard solution (ULOQ) in a blank matrix (STD BL) at RT of analytes. To check the auto-sampler carryover blank sample, ULOQ and lower limit of quantification (LLOQ) were processed as per the extracted sample preparation. These samples were acquired by auto-sampler in a sequence of STD BL, ULOQ, STD BL and LLOQ in order to evaluate the carryover. The acceptance criteria for carryover were set at $20 \%$ of the peak area corresponding to the LLOQ level as per the EMA guidelines for bioanalysis.

\subsubsection{Linearity, accuracy and precision}

To determine the linearity, accuracy and precision, three precision and accuracy batches (P\&A) consisting of one STD BL (blank matrix), STD 1 to STD 12, six sets each of HQC, MQC and LQC or HQC and LQC were performed on three separate days. All the samples including QCs were prepared freshly on each analysis day. The calibration curve was constructed by plotting the peak area ratio (standard/labelled standard) versus the concentration at a range of 0.5 to $2500 \mathrm{ng} / \mathrm{mL}$; the linearity of the method was determined by using a $1 / \mathrm{x}^{2}$ weighted least-squares regression analysis of a normal plot associated with a 12-point standard curve. The accuracy and precision were evaluated using QCs prepared and analysed on three separate days. The accuracy was evaluated by measuring the mean accuracy at each concentration level of the calibration curve standard and QCs, calculated as the measured value divided by the nominal value. The inter- and intra-batch variability was calculated by measuring \% CV at each concentration level of QCs.

\subsubsection{Recovery and matrix effect}

The recovery and matrix effect experiments were performed at high-, middle- and low-concentration levels. The analytes were spiked either before (spiked samples) or after (post-spiked samples) extraction at the concentration equivalent to those in the low-, middle- and highQC extracted samples ( $\mathrm{n}=6$ at each level). Additionally, analytes were spiked in an aqueous solvent to obtain samples free of the matrix. The recovery was calculated using the ratio of the mean peak area of the spiked samples to the mean peak area of the post-spiked samples. The matrix effect was evaluated by calculating a matrix factor to check the variability. The mean peak area in the presence of matrix ions (area of post-spiked samples) and the mean peak area in the absence of matrix ions (area of aqueous spiked samples) was calculated. The matrix factor was calculated by dividing the mean peak area in the presence of matrix ions by the mean peak area in the absence of matrix ions.

\subsubsection{Stability}

Different stabilities, such as wet extract stability, freeze-thaw stability and stock solution stability, were determined during validation. Wet extract stability was assessed using the re-injection of samples stored in the auto-sampler. After a full P\&A batch was run, six replicates of HQC and LQC vials were kept in the auto-sampler at $5{ }^{\circ} \mathrm{C}$. To determine the stability, the same samples in the same sequence were reinjected with fresh QC samples, and the results were compared. The freeze-thaw stability was evaluated during up to three cycles by freezing and thawing the spiked samples stored at $-80^{\circ} \mathrm{C}$. Three replicates of QCs were stored at $-80^{\circ} \mathrm{C}$ and after $24 \mathrm{~h}$, these samples were retrieved and thawed at room temperature. These samples were stored back in freezer for freezing and after $12 \mathrm{~h}$ again retrieved and thawed at room temperature. This step was repeated again and after that the samples were analysed. We assessed the stability by comparing the concentration against the freshly spiked samples. Stock solution stability was evaluated by comparing the mean peak area of fresh stock solutions to the stored stock solutions stored at $-20 \pm 5{ }^{\circ} \mathrm{C}$.

\subsubsection{Limit of detection and limit of quantification}

LOD and LOQ were defined as the lowest analyte concentrations yielding a signal-to-noise $(\mathrm{S} / \mathrm{N})$ ratio of 3 and 10 , respectively. We have used empirical approaches to minimise the random error and estimates the expected precision of a series of measurements of analytical signal for measurement of LOD and LOQ values [10,15]. The experiment commenced with the serial dilution of the final extract of the spiked samples. These samples were then analysed along with the blank samples in replicates of three for individual concentrations using each extraction method.

\section{Results and discussion}

\subsection{Method development}

\subsubsection{Method optimisation}

We employed the UHPLC-MS/MS method with electro spray ionisation due to the selectivity, sensitivity and reproducibility of this technique. The use of positive ESI resulted in good ionisation of the analytes and $[\mathrm{M}+\mathrm{H}]^{+}$ions were chosen as precursor ions. The selection of the product ion producing the highest response further 

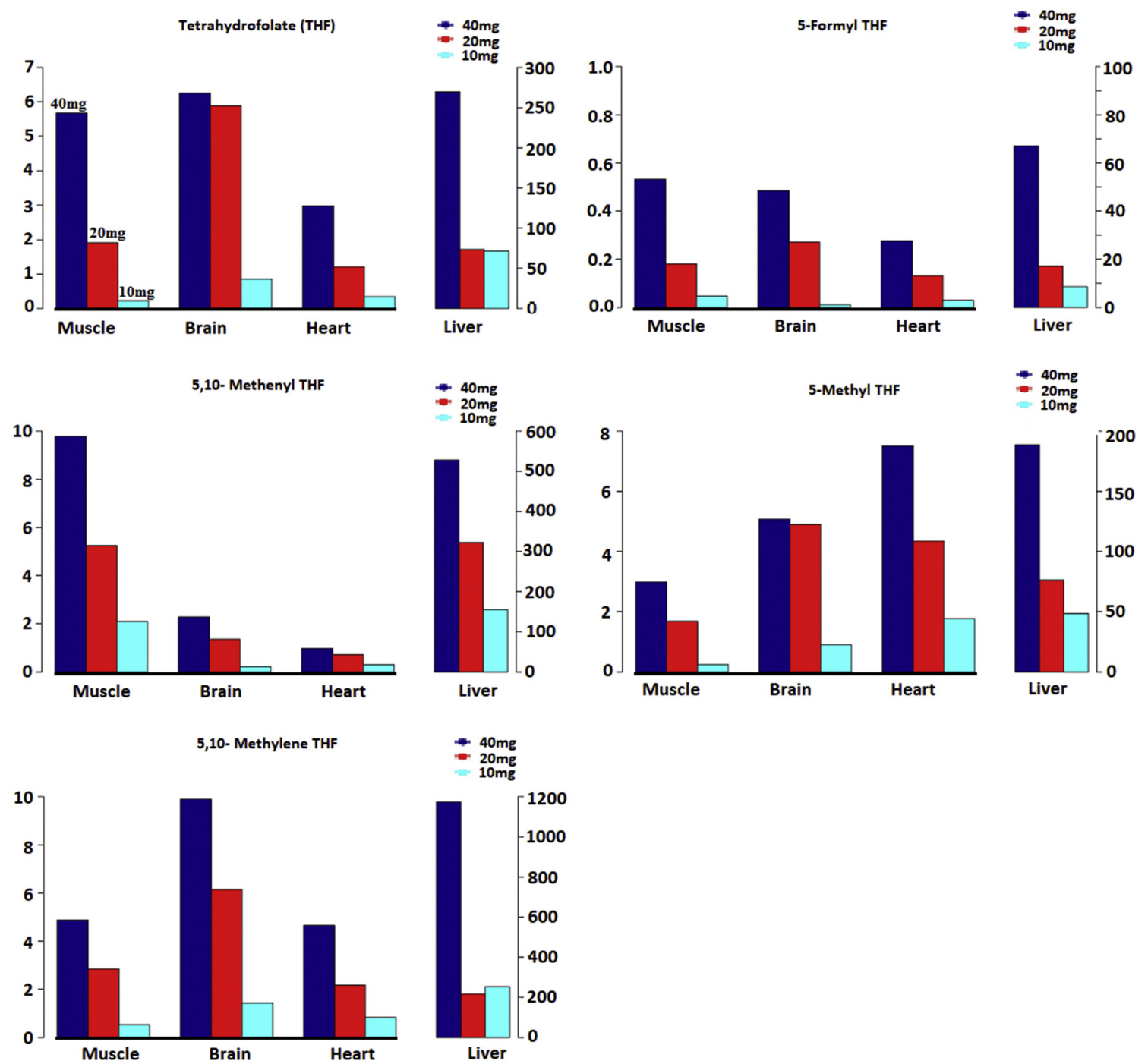

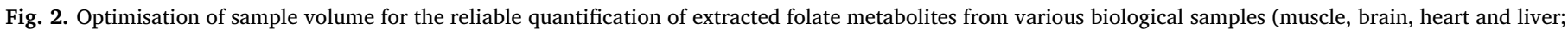
$\mathrm{n}=6$ ). The $\mathrm{y}$ axis shows the average concentration (ppb) of the respective folate metabolites.

improved the selectivity and sensitivity of the method. Different stationary phase and mobile phase compositions were tested, and finally the most optimal separation, peak shape and response was obtained in an Atlantis $\mathrm{dC}_{18} 2.0 \times 100 \mathrm{~mm}, 3-\mu$ column with $0.1 \%$ formic acid in water $(\mathrm{v} / \mathrm{v})$ and an acetonitrile mobile phase in the gradient elution mode.

Folate metabolites are unstable since they are very sensitive to light, oxidants and $\mathrm{pH}$. Additionally, they are interconvertible depending upon the $\mathrm{pH}$ of the extraction buffer [8-10]. Most folate metabolites are stable between $\mathrm{pH} 5$ and 10 when not exposed to elevated temperatures. Ascorbic acid along with $\beta$-mercaptoethanol has been shown to prevent interconversion and the further oxidative degradation of folate metabolites $[8,10]$. Thus, all stock and working solutions were prepared in a HEPES buffer ( $\mathrm{pH}$ 8.0) containing both of the abovementioned chemicals. We found that the standard solutions were stable up to two months after storage at $-20^{\circ} \mathrm{C}$. However, they were stored at a high concentration to prevent degradation and interconversion since the stability of 5,10-methylene THF, THF and 5,10-methenyl THF is concentration-dependent [10]. Most endogenous folates are present as polyglutamates in biological materials, and thus their cleavage to monoglutamates is necessary in order to quantify pure folate metabolites $[11,12]$. We used charcoal-treated rat plasma as a source of pteroylpoly- $\gamma$-glutamylcarboxypeptidase for folate deconjugation since this enzyme has an optimum $\mathrm{pH}$ at approximately 7.5. For deconjugation, we incubated samples for $3 \mathrm{~h}$ at $37^{\circ} \mathrm{C}$ as in previous studies [10-12]. For instance, Fazili et al. [12] demonstrated that the intensity of the signal was high for all folate metabolites tested, particularly for 5-methyl THF, in samples incubated for $3 \mathrm{~h}$. We selected homogenisation method for extraction since it is simple and minimize rapid degradation of folate metabolites. We chose a HEPES buffer ( $\mathrm{pH} \mathrm{8.0)}$ as the extraction buffer after testing various buffer compositions. We obtained an acceptable chromatography and sensitivity using this buffer, which was important since the final extract was injected without further treatment. Additionally, we found that the folates of interest were stable in a HEPES buffer ( $\mathrm{pH}$ 8.0) and obtained a satisfactory recovery and reproducibility for the tissue and cell samples. However, we observed a low recovery and high matrix effect for whole blood samples using the same protocol and, thus, chose SPE extraction to achieve cleaner extracts and an increased recovery. Almost all folates have an acidic pKa value; we, therefore, selected SPE with a strong anion exchange mechanism. Various SPE cartridges from different vendors were tested to obtain a good extraction efficiency. The best results were obtained using Strata-X anion exchange SPE cartridges. Furthermore, for the optimisation of the extraction method, we combined several extraction buffers, washing solutions and elution solutions to obtain an adequate recovery with a minimum loss of folate metabolites. In general, a low $\mathrm{pH}$ is required to retain folates using SPE since it also enables the release of protein-bound folate. However, stability may become an 
Compound name Folic acid Correlafon coeficient $r=0.993802, r^{\wedge} 2=0.997643$ Calibration curve $0.00457376^{ \pm} x+0.00115809$ Responsetype Internal Std (Ref 14), Area * (IS Conc. /ISArea) Curve type Linear, Origin: Exclude, Weighing: $1 x^{\wedge} 2$, Avis trans: None

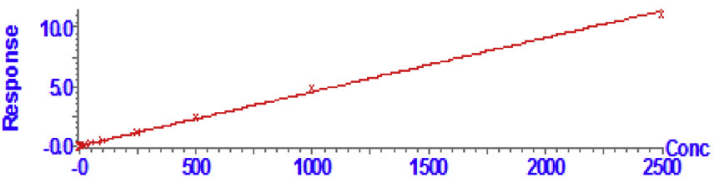

Compound name Tetrahycrofdate

Correlation coefficient $r=0.997440, r^{\wedge} 2=0.994886$ Calibration curver $0.0194709^{*} x+-0.000439626$ Responsetype Internal Std (Ref 14), Area ${ }^{*}$ (IS Conc. IIS Area) Curve type Linear, Origin: Exclude, Weighing: $1 / x^{\wedge} 2$, Axis trans: None

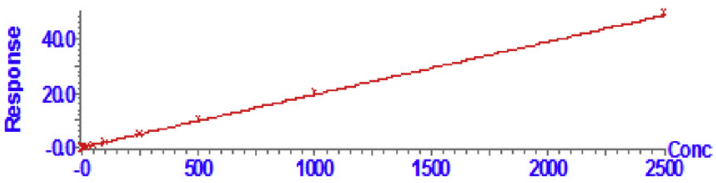

Campound narze 5,10methenyl tetrahydrofolate

Campound name 5,10-methenyl tedrahydrofdate
Carelaion coeficient $r=0.996173, r^{\mathrm{m} 2}=0.992360$ Carrelation coeficient: $r=0.996173, r^{2} 2=0.992260$
Calibration curve $0.0104551^{*} x+-0.000429721$ Responsetype Internal Std (Ref 14 ), Area * (IS Conc. / IS Area) Curve type Linear, Origin: Exclude, Weighing: 1/ $x^{\wedge} 2$, Avis trans: None

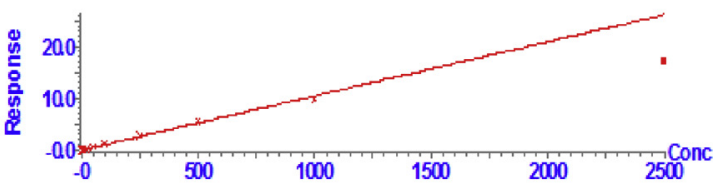

Compound nane 5 -medtyltetrahydrofolate

Campound nane 5 mediny/ tetrahydrodolate
Carelafan coeficient $\mathrm{r}=0.996657, \mathrm{r}^{\wedge} 2=0.993326$

Carelaían coeficient, $r=0.996657, r^{\wedge} 2=0.9933$

Calibration curve $0.0298239^{*} x+0.000625929$

Responsetype Irternal Std(Re 14), Area * (IS Conc. /IS Area)

Curve type Linear, Origin: Exclude, Weighing: 1/ $x^{\wedge} 2$, Axis trans: None

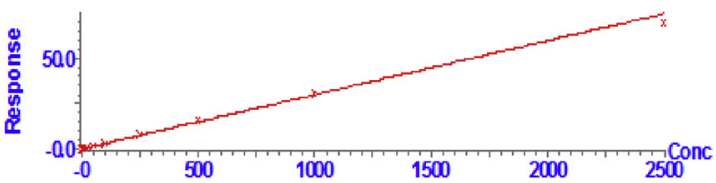

Compound nare 5,10-methylenetetrahydiofolate

Correlafon coeficient $\mathrm{r}=0.993565, \mathrm{r}^{2} 2=0.98717$

Callibration curve $0.00490487^{\star} \mathrm{x}+-0.00125565$

Responsetype Internal Std (Ref 14 ), , Area * (IS Conc. /IS Area)

Curve type Linear, Origin: Exclude, Vkighing: $1 / x^{\wedge} 2$, Axis trans; None

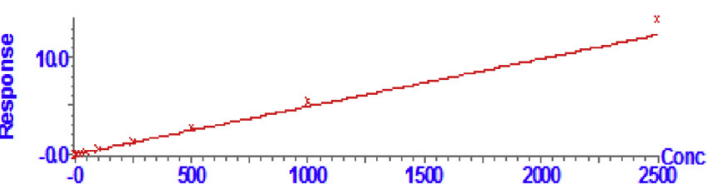

Campound nare 5 farmyl tetrahydrofdate

Carrelaín coeficient $r=0.993090, r^{\wedge} 2=0.986228$

Calibration curve $0.0149115^{*} \mathrm{X}+-7.83672 \mathrm{e}-005$

Responsetype Intermal Std (Ref 14 ), Area ${ }^{*}$ (IS Conc. / ISArea )

Curve type Linear, Origin: Exclude, Weighing: 1/k^2, Axis trans: None

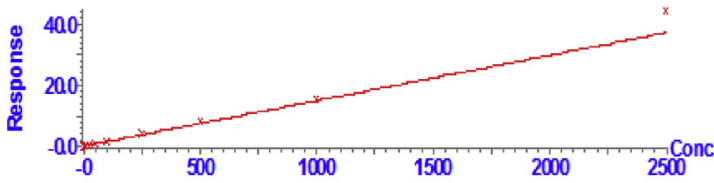

Compound name Dihycrofolate

Correlafon coefficient $r=0.991357, r^{\wedge} 2=0.982789$

Calibration curve $0.00338479^{*} \mathrm{x}+-0.00293535$

Responsetype Internal Std (Ref 14 ), Area ${ }^{ \pm}$(IS Conc. /IS Area)

Curve type Linear, Origin: Exclude, Weighing: $1 x^{\wedge} 2$, Axis trans: None

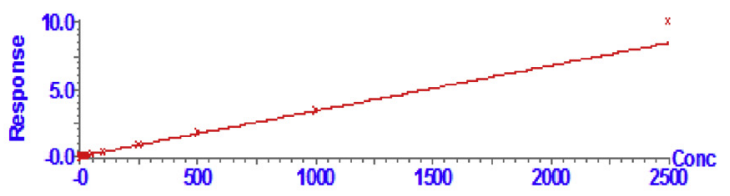

Fig. 3. Linearity in concentrations ranging from 0.5 to $2500 \mathrm{ng} \backslash \mathrm{mL}$ of the calibration curve for folate metabolites with a weighing factor of $1 / \mathrm{x}^{2}$.

Table 2

Results of recovery, intra- and inter-day precision of folate metabolites in mouse muscle tissue.

\begin{tabular}{|c|c|c|c|c|c|c|}
\hline \multirow[t]{2}{*}{$\begin{array}{l}\text { Compound } \\
\text { name }\end{array}$} & \multirow[t]{2}{*}{$\begin{array}{l}\text { Linearity } \\
\mathrm{r}^{2} \text { value }^{\mathrm{a}}\end{array}$} & \multicolumn{2}{|c|}{$\begin{array}{l}\text { Intra-day precision } \\
\text { of high and low } \\
\text { concentrations, \% } \\
\text { RSD }\end{array}$} & \multicolumn{2}{|c|}{$\begin{array}{l}\text { Inter-day precision } \\
\text { of high and low } \\
\text { concentrations, \% } \\
\text { RSD }\end{array}$} & \multirow[t]{2}{*}{$\begin{array}{l}\text { Mean } \\
\text { recovery } \\
(\%)^{\mathrm{b}}\end{array}$} \\
\hline & & $\begin{array}{l}800 \mathrm{ng} / \\
\mathrm{mL}\end{array}$ & $\begin{array}{l}1.0 \mathrm{ng} / \\
\mathrm{mL}\end{array}$ & $\begin{array}{l}800 \mathrm{ng} / \\
\mathrm{mL}\end{array}$ & $\begin{array}{l}1.0 \mathrm{ng} / \\
\mathrm{mL}\end{array}$ & \\
\hline Folic acid & 0.984 & 1.56 & 10.45 & 1.58 & 17.27 & 91.25 \\
\hline $\begin{array}{c}\text { Tetrahydrofolic } \\
\text { acid (THF) }\end{array}$ & 0.991 & 1.50 & 0.94 & 2.97 & 1.09 & 93.45 \\
\hline $\begin{array}{l}\text { 5,10-Methylene } \\
\text { THF }\end{array}$ & 0.988 & 3.51 & 0.98 & 3.26 & 2.13 & 92.05 \\
\hline $\begin{array}{l}\text { 5,10-Methenyl } \\
\text { THF }\end{array}$ & 0.991 & 5.73 & 1.60 & 4.11 & 2.70 & 95.41 \\
\hline 5-Formyl THF & 0.998 & 4.50 & 8.47 & 6.75 & 10.96 & 93.07 \\
\hline 5-Methyl THF & 0.994 & 6.74 & 8.79 & 8.58 & 6.51 & 91.18 \\
\hline $\begin{array}{l}\text { Dihydrofolic } \\
\text { acid }\end{array}$ & 0.997 & 8.67 & 10.94 & 12.45 & 14.68 & 86.64 \\
\hline
\end{tabular}

${ }^{a}$ Lowest $r^{2}$ value across three calibration sets during validation.

b Mean recovery.

issue at a very low $\mathrm{pH}$ as endogenous 5,10-methenyl THF converts to 10-formyl THF and 5,10-methylene THF converts to THF [9, 10]. A HEPES buffer ( $\mathrm{pH} 8.0$ ) was ideal, preventing degradation and the loss of folates, but recovery was very low perhaps due to the insufficient retention of folates on SPE at this pH. Finally, adjusting the $\mathrm{pH}$ of the HEPES extraction buffer to 5.0 proved a suitable compromise in order to achieve sufficient recovery with less degradation and interconversion. We encountered similar problems when optimising the $\mathrm{pH}$ during elution, since acidic conditions were required for the ion exchange and to elute the folate metabolites. We did not obtain 5,10-methylene THF at a low $\mathrm{pH}(\mathrm{pH} 2-3)$ due to its instability during extraction with SPE, while we obtained an acceptable recovery using an elution solution with $\mathrm{pH}$ 5.0. Acetonitrile was added to the elution solution since it increased the response of 5-formyl THF and 5-methyl THF by almost $20 \%$, while the use of methanol lead to less noise in LC-MS. We used an isotope labelled 5-methyl THF as an internal standard to correct for any potential loss of metabolites during sample preparation and due to the matrix effect except during the interconversion of folate metabolites. The matrix effect was found less often when using the extraction method described above and did not affect the final results due to the structural similarity of the internal standard for almost all folates.

\subsubsection{Folate interconversion}

To test folate interconversion, we selected the liver since the concentration of folates is highest there among tested tissues. Tissue samples were homogenised and 16 aliquots were made. Individual folate standards were spiked into respective aliquots in two replicates. Two aliquots were processed without spiking to check the endogenous 
Table 3

Results of recovery, intra- and inter-day precision of folate metabolites in human whole blood.

\begin{tabular}{|c|c|c|c|c|c|c|c|c|}
\hline \multirow[t]{2}{*}{ Compound name } & \multirow[t]{2}{*}{$\begin{array}{l}\text { Linearity } \mathrm{r}^{2} \\
\text { value }^{\mathrm{a}}\end{array}$} & \multicolumn{3}{|c|}{$\begin{array}{l}\text { Intra-day precision of high, middle and low } \\
\text { concentrations, \%RSD }\end{array}$} & \multicolumn{3}{|c|}{$\begin{array}{l}\text { Inter-day precision of high, middle and low } \\
\text { concentrations, \%RSD }\end{array}$} & \multirow[t]{2}{*}{$\begin{array}{l}\text { Mean recovery } \\
(\%)^{\mathrm{c}}\end{array}$} \\
\hline & & $800 \mathrm{ng} / \mathrm{mL}$ & $400 \mathrm{ng} / \mathrm{mL}$ & $1.0 \mathrm{ng} / \mathrm{mL}$ & $800 \mathrm{ng} / \mathrm{mL}$ & $400 \mathrm{ng} / \mathrm{mL}$ & $1.0 \mathrm{ng} / \mathrm{mL}$ & \\
\hline Folic acid & 0.988 & 21.82 & 19.60 & 26.35 & 23.91 & 16.74 & 24.36 & 18.62 \\
\hline Tetrahydrofolic acid (THF) & 0.988 & 7.04 & 9.18 & 12.54 & 20.44 & 9.80 & 16.54 & 76.90 \\
\hline 5,10-Methylene THF & 0.994 & 30.39 & 26.76 & 28.54 & 36.69 & 34.41 & 32.54 & 123.56 \\
\hline 5,10-Methenyl THF & 0.987 & 19.74 & 10.44 & 22.64 & 12.67 & 10.09 & 18.24 & 91.69 \\
\hline 5-Formyl THF & 0.994 & 7.26 & 7.99 & 10.54 & 18.42 & 9.81 & 16.65 & 58.62 \\
\hline 5-Methyl THF & 0.997 & 5.23 & 3.33 & 10.54 & 12.73 & 15.06 & 14.33 & 111.56 \\
\hline Dihydrofolic acid & 0.995 & $\mathrm{ND}^{\mathrm{b}}$ & $\mathrm{ND}^{\mathrm{b}}$ & $\mathrm{ND}^{\mathrm{b}}$ & $\mathrm{ND}^{\mathrm{b}}$ & $\mathrm{ND}^{\mathrm{b}}$ & $\mathrm{ND}^{\mathrm{b}}$ & $\mathrm{ND}^{\mathrm{b}}$ \\
\hline
\end{tabular}

a Lowest $\mathrm{r}^{2}$ value across three calibration sets during validation.

b Could not be determined from whole blood.

c Mean recovery.
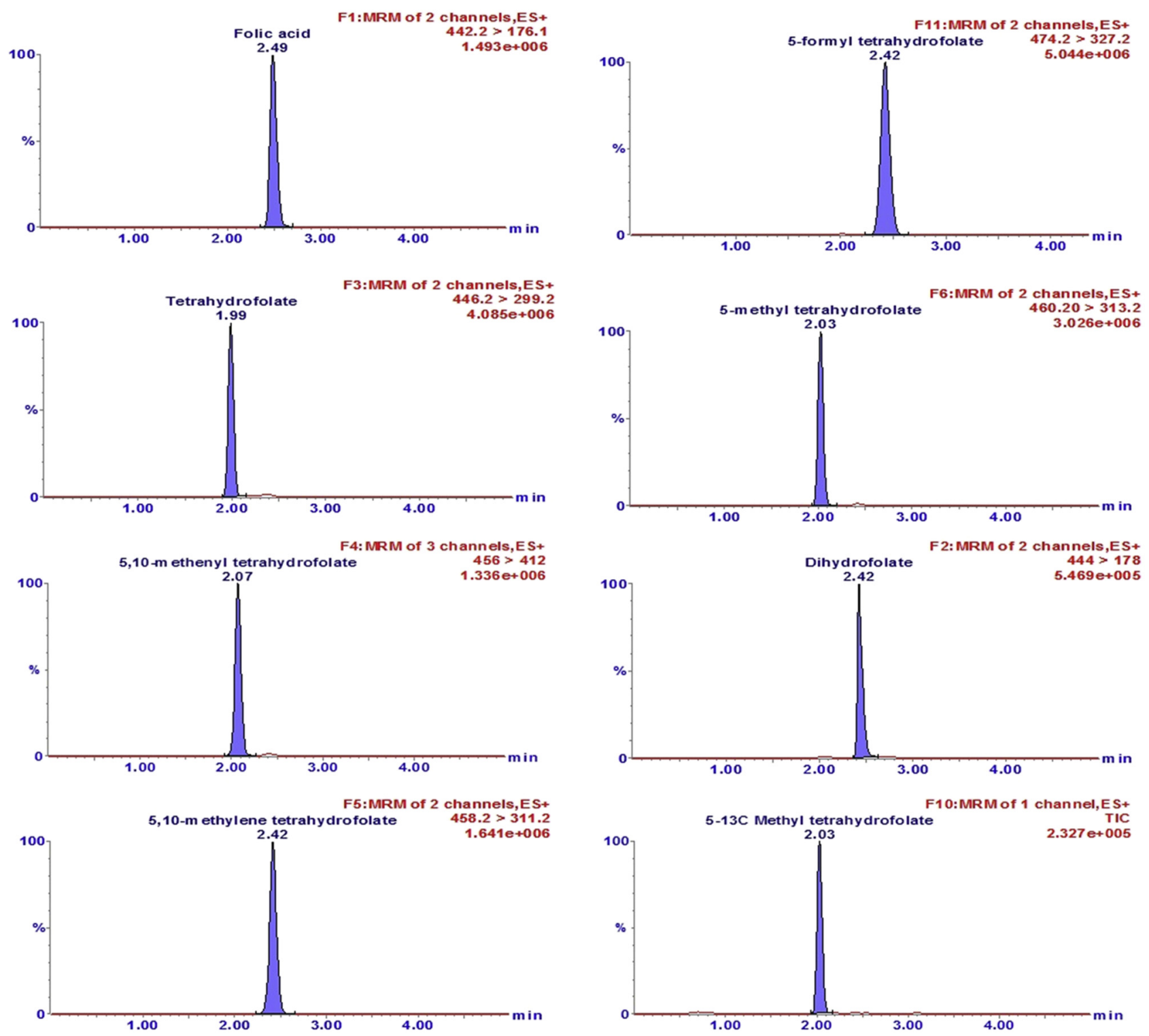

Fig. 4. Chromatograms showing the peak shape, retention time and mass transition for all folate metabolites during muscle tissue sample analysis.

concentration of the folates. All samples were processed according to the tissue protocol, and interference from the folate metabolites was checked by examining their respective chromatograms. We observed that approximately $27 \%$ of dihydrofolate is converted to folic acid; approximately $40 \%$ of 5,10 -methylene THF is converted to THF and $2.3 \%$ of 5,10 -methenyl THF is converted to 5 -formyl THF. The high conversion rate of 5,10-methylene THF to THF might be due to the acidic mobile phase. 

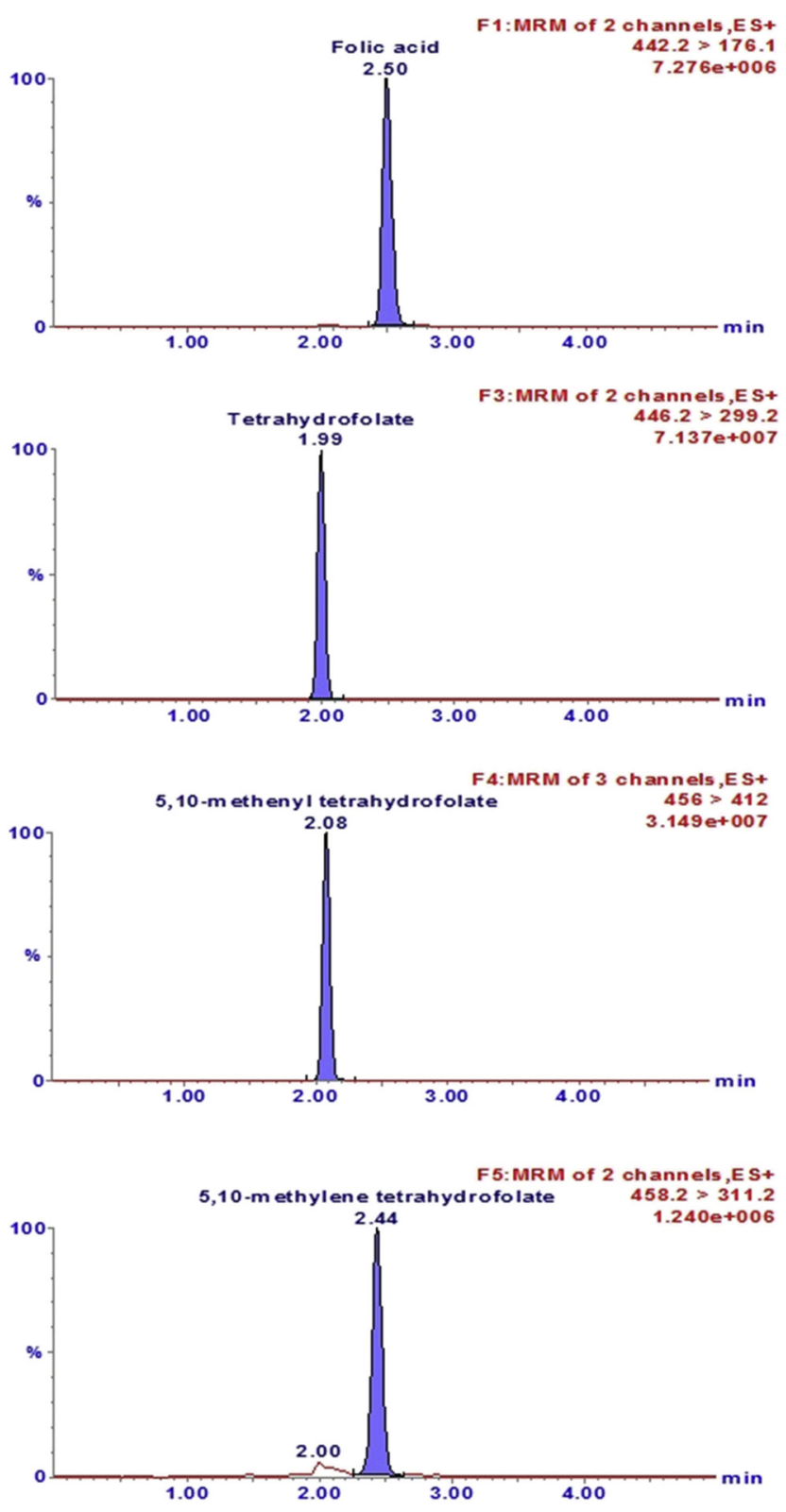

Fig. 5. Chromatograms showing the peak shape, retention time and mass transition for all folate metabolites during whole blood sample analysis.

\subsubsection{Sample volume optimisation}

In order to identify the minimum sample requirement, different sample weights-that is, 10,20 and $40 \mathrm{mg}$-were tested for folate extraction (Fig. 2). We found that for $10 \mathrm{mg}$ of tissue the concentration values of folate metabolites were below the lower limit of quantification (BLLOQ) or near LOQ (except in the liver tissue samples) with poor chromatography results, particularly for 5-formyl THF. However, the chromatography and response performed well for all metabolites when $20 \mathrm{mg}$ of tissue was used. Yet, we found a response near LOQ for 5-formyl THF and for 5-methenyl THF in every tissue type except the liver tissue samples. Thus, we calculated $\% \mathrm{CV}$ of the response for all metabolites to check for variation. We found that $\% \mathrm{CV}$ of the response fell to $18.31 \%$ for all metabolites across all tissue types except for 5,10-methenyl THF ( $\% \mathrm{CV}=28.17 \%$ in the muscle tissue samples) and for 5 -formyl THF (\% CV $=56.61 \%$ in the muscle tissue samples and $20.96 \%$ in the brain tissue samples). Yet, the \% CV of the response was $12.49 \%$ for all metabolites across all tissue types with a $40 \mathrm{mg}$ tissue weight. Thus, while we obtained an acceptable response and chromatography profile using $20 \mathrm{mg}$ of tissue, $40 \mathrm{mg}$ yielded more accurate
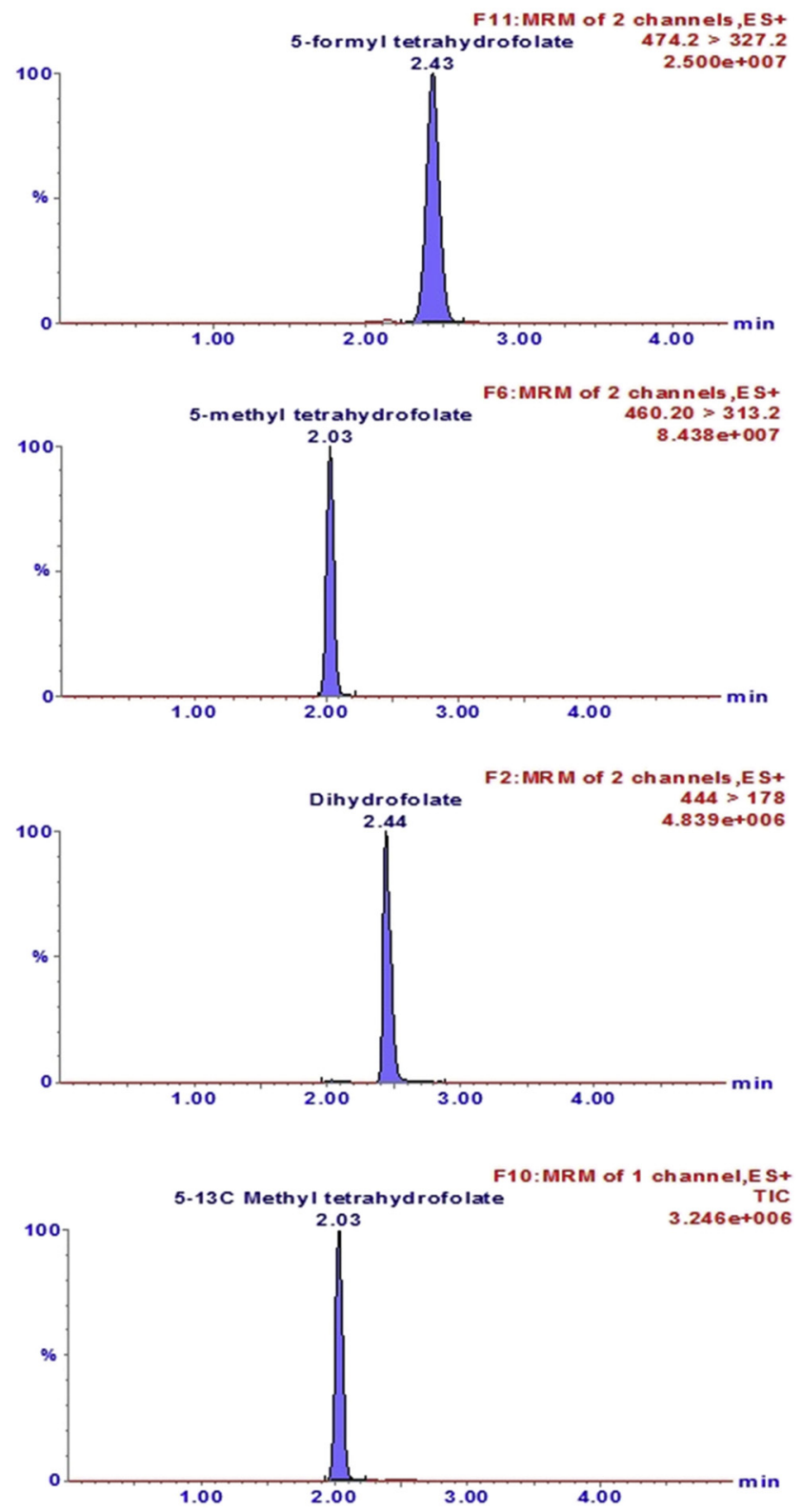

and more reliable results.

\subsection{Method validation}

\subsubsection{Auto-sampler carryover}

We observed no significant carryover in the STD BL sample in this experiment. We calculated the carryover as the percentage of the peak area obtained from a blank sample chromatogram after injection with ULOQ compared to the peak area of LLOQ. The peak area for the retention time of the analytes in blank samples for all folate metabolites reached no more than $20.00 \%$ of the LLOQ area.

\subsubsection{Linearity, accuracy and precision}

All calibration curves analysed during validation were linear for the standards ranging from 0.5 to $2500 \mathrm{ng} / \mathrm{mL}$. A straight-line fit was calculated through the data points using least-squares regression analysis, for which we observed a constant proportionality. Furthermore, the back-calculated concentration of the standards fell within the acceptance criteria using the linear model. Different weighting factors, 
Table 4

Summary of stability results for all folate cycle metabolites.

\begin{tabular}{|c|c|c|c|c|c|}
\hline \multirow{2}{*}{$\begin{array}{l}\text { Compound } \\
\text { name }\end{array}$} & \multicolumn{2}{|c|}{ Whole blood } & \multicolumn{2}{|c|}{ Tissue (muscle) } & \multirow{2}{*}{$\begin{array}{l}\text { Stock } \\
\text { solution } \\
\text { stability } \\
(\%)^{\mathrm{a}}\end{array}$} \\
\hline & $\begin{array}{l}\text { Wet } \\
\text { extract } \\
\text { stability } \\
(\%)^{\mathrm{a}}\end{array}$ & $\begin{array}{l}\text { Freeze-thaw } \\
\text { stability }(\%)^{\mathrm{a}}\end{array}$ & $\begin{array}{l}\text { Wet } \\
\text { extract } \\
\text { stability } \\
(\%)^{\mathrm{a}}\end{array}$ & $\begin{array}{l}\text { Freeze-thaw } \\
\text { stability }(\%)^{\mathrm{a}}\end{array}$ & \\
\hline Folic acid & $101.88^{\mathrm{b}}$ & $111.96^{\mathrm{b}}$ & 95.25 & 93.31 & 98.89 \\
\hline $\begin{array}{c}\text { Tetrahydrofolic } \\
\text { acid (THF) }\end{array}$ & 105.75 & 102.36 & 94.70 & 91.26 & 98.72 \\
\hline $\begin{array}{l}\text { 5,10-Methylene } \\
\text { THF }\end{array}$ & 152.26 & 138.13 & 91.59 & 91.23 & 90.33 \\
\hline $\begin{array}{l}\text { 5,10-Methenyl } \\
\text { THF }\end{array}$ & 56.30 & 79.20 & 88.20 & 91.45 & 86.10 \\
\hline 5-Formyl THF & 106.54 & 101.77 & 86.67 & 89.88 & 103.50 \\
\hline 5-Methyl THF & 97.63 & 103.30 & 97.74 & 91.45 & 89.88 \\
\hline $\begin{array}{l}\text { Dihydrofolic } \\
\text { acid }\end{array}$ & $\mathrm{ND}^{\mathrm{c}}$ & $\mathrm{ND}^{\mathrm{c}}$ & 86.25 & 92.45 & 78.68 \\
\hline
\end{tabular}

a \% mean stability.

b Stability at a high concentration level.

c Could not be determined from whole blood.

including no weighting factor, $1 / \mathrm{x}$ and $1 / \mathrm{x}^{2}$, were applied to yield the best linear regression model. We found a minimum absolute error applying the $1 / \mathrm{x}^{2}$ weighting factor. The regression coefficient values for each folate metabolite were $>0.980$ (Fig. 3). The mean precision and accuracy observed for all calibration curve standards did not exceed $15 \%$. We calculated the precision for QC samples by measuring \%RSD at each QC concentration level. In general, intra- and inter-day precision (\%RSD) values were within $15 \%$ for the muscle tissue samples and within $25 \%$ for the whole blood samples. However, 5,10-methylene THF yielded high values of \%RSD (up to $36.69 \%$ ) for the whole blood samples. Tables 2 and 3 provide the regression coefficients and intraand inter-day precision values for each folate metabolite for the muscle tissue and whole blood, respectively. Figs. 4 and 5 show the chromatograms for the folate metabolites during validation in the muscle tissue and whole blood samples, respectively.

\subsubsection{Recovery and matrix effect}

Given that folate metabolites were relatively stable in a HEPES buffer (pH 8.0), the recovery of all folate metabolites was excellent in the muscle tissue samples, reaching values between $86.64 \%$ and $95.41 \%$ (Table 2). However, the recoveries were not as good in the whole blood samples with values falling between $58.62 \%$ and $123.56 \%$ (Table 3). This demonstrates the necessity of using the respective isotope labelled internal standards to compensate for the loss of metabolites and interconversion. In the whole blood samples, the recovery of folic acid remained low because this compound ionised at a very low $\mathrm{pH}$. Additionally, we detected no dihydrofolic acid from the whole blood samples due to its instability at a $\mathrm{pH}$ below 7 . The matrix effect values were acceptable in the muscle tissue varying from between 0.76 and 1.28. For the whole blood, we found matrix effect values of 0.54 to 0.70 , except for 5,10-methylene-THF where the matrix factor value reached 1.86. These results show that some matrix effect existed, which could be compensated for using the labelled internal standard for each analyte. However, the matrix effect variability at each level, as measured by the coefficient of variation, reached $<25 \%$, thus explaining the reproducible results.

\subsubsection{Stability}

Because the folate metabolites are unstable, particularly 5,10-methenyl THF and 5,10-methylene THF, we determined the stability of folates in a final extract, in stock solutions and during the freeze-thaw cycle. Folate metabolites extracted from the whole blood and tissue samples were stable for $14 \mathrm{~h}$ at $5^{\circ} \mathrm{C}$ after extraction. This did not hold for 5,10-methenyl THF or for 5,10-methylene THF extracted from
Table 5

Summary of LOD and LOQ values (nmol $\backslash$ L) for folate metabolites in final extract.

\begin{tabular}{lllll}
\hline Compound name & $\begin{array}{l}\text { Muscles } \\
\text { tissue extract } \\
\text { (LOD) }\end{array}$ & $\begin{array}{l}\text { Whole } \\
\text { blood } \\
\text { extract } \\
\text { (LOD) }\end{array}$ & $\begin{array}{l}\text { Muscles } \\
\text { tissue extract } \\
\text { (LOQ) }\end{array}$ & $\begin{array}{l}\text { Whole } \\
\text { blood } \\
\text { extract } \\
\text { (LOQ) }\end{array}$ \\
\hline Folic acid & 0.566 & - & 1.133 & 2.266 \\
Tetrahydrofolic acid & 0.337 & 0.225 & 1.123 & 1.123 \\
$\quad$ (THF) & & & & \\
5,10-Methylene THF & 0.329 & 0.219 & 1.095 & 1.095 \\
5,10-Methenyl THF & 0.547 & 0.656 & 1.094 & 1.094 \\
5-Formyl THF & 0.317 & 0.317 & 1.056 & 1.056 \\
5-Methyl THF & 0.327 & 0.218 & 1.089 & 1.089 \\
Dihydrofolic acid & 0.677 & - & 1.353 & - \\
\hline
\end{tabular}

whole blood since their stability fell outside the range of $85 \%$ and $115 \%$. This demonstrates that $\mathrm{pH}$ and the presence of an antioxidant in the elution solution does not completely protect folate from degradation and interconversion. Thus, the use of a one-to-one isotope labelled internal standard is essential to compensate for the losses and ensures the most accurate quantification. Furthermore, the freeze-thaw stability after three freeze-thaw cycles was also acceptable without any significant degradation of the folate metabolites. We found a stability falling within $85 \%$ and $115 \%$ for each folate metabolite during the freeze-thaw cycles, except for 5,10-methylene THF and 5,10-methenyl THF, where stability reached $138.13 \%$ and $79.20 \%$, respectively, in the whole blood samples. All folate metabolite stock solutions were stable for 2 months at $-20^{\circ} \mathrm{C}$. The stock solution stability fell within $85 \%$ and $115 \%$ for all folate cycle metabolites, except for dihydrofolic acid, which reached $78.68 \%$. Table 4 provides a summary of the stability experiment results.

\subsubsection{Limit of detection and limit of quantification}

Using a signal-to-noise ratio of 3 as the cut-off, we calculated the LOD values of the folate metabolites from the final extract of the muscle tissue and whole blood samples as shown in Table 5. With a signal-tonoise ratio of 10 as the cut-off, we obtained LOQ of $0.5 \mathrm{ng} / \mathrm{mL}$ for all metabolites except for folic acid and dihydrofolic acid in the whole blood samples, which could not be determined due to the low recovery as mentioned in Table 5.

\section{Biological sample analysis}

We applied the developed and validated analytical method to determine the distribution of folate cycle metabolites in human whole blood and mouse plasma. We also examined different mouse tissue samples including muscle, heart, liver and brain samples from CD5 mice 7- to 12-weeks old and bone marrow cells (Fig. 6). In the brain, the total folate concentration, including all seven folate metabolites, reached $0.045 \mu \mathrm{mol} / \mathrm{g}$ with a dominant concentration of THF $(50 \%$ of the total folate). The folate content in the heart tissue samples was $0.046 \mu \mathrm{mol} / \mathrm{g}$ with a THF concentration of $40 \%$ and a 5-methyl THF concentration of $35 \%$. The total folate concentration in the muscle tissue samples was $0.017 \mu \mathrm{mol} / \mathrm{g}$, which is 2.7 times lower than in the heart and muscle tissue samples, but with a similar relative amount of 5 -methyl THF accounting for $40 \%$ of the total folate pool, indicating a high rate of re-methylation reactions in these tissues. The liver tissue had the highest total folate content reaching values of $1.815 \mu \mathrm{mol} / \mathrm{g}$ reflecting its high demands in one-carbon units especially for re-methylation reactions. Since the liver has a high metabolic rate, the relative amount of 5-methyl THF is lower than that in the muscle tissue, while the amount of its precursor 5,10-methylene THF is elevated. The total folate concentration measured in human blood was $155.59 \mathrm{ng} / \mathrm{mL}$, which is similar to the value of $<150 \mathrm{ng} / \mathrm{mL}$ reported in the Human Metabolome Database (HMDB data). The total folate concentration in 


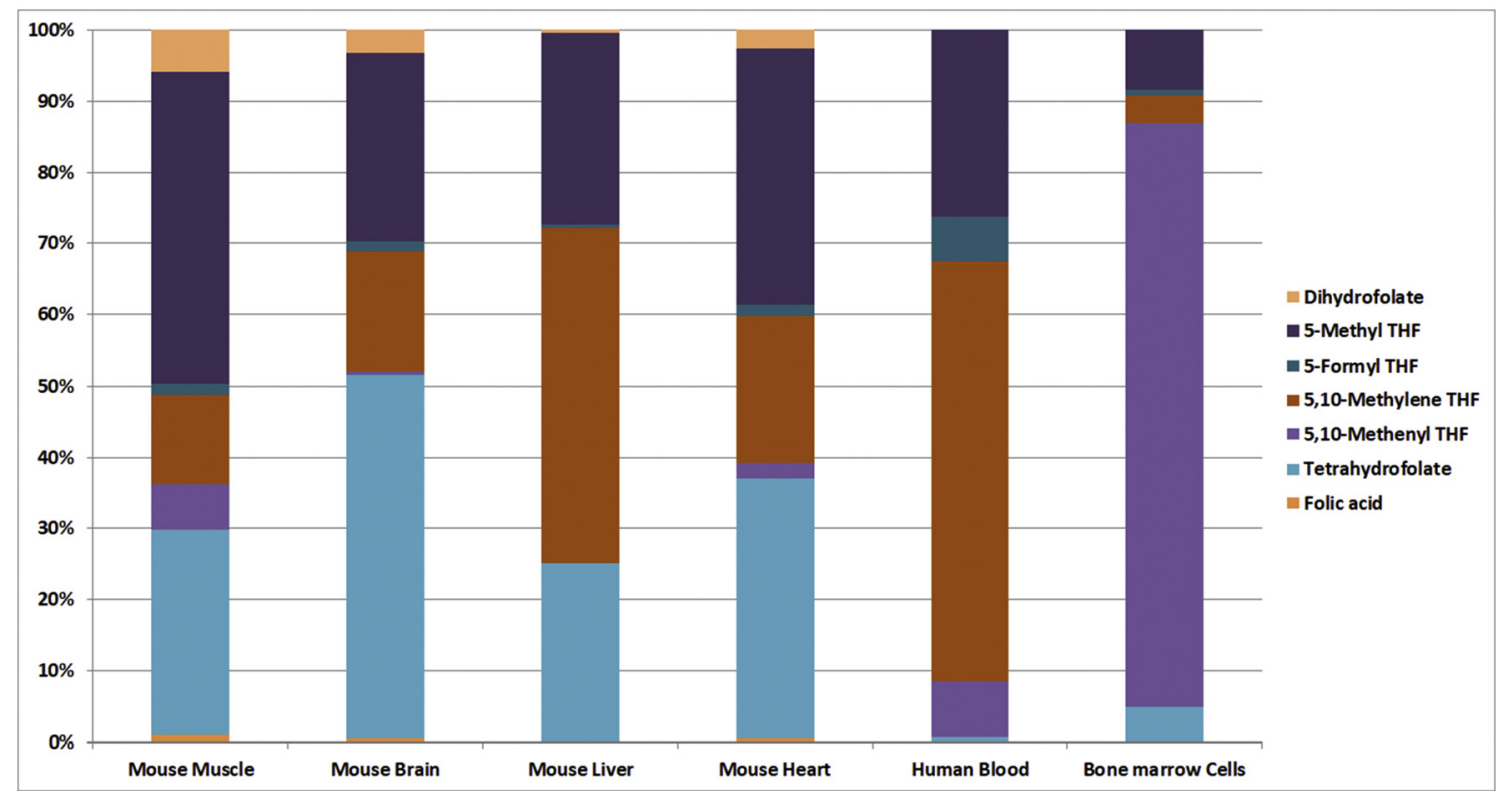

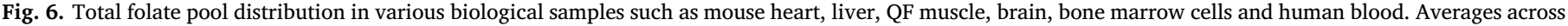
six replicates were used to determine the folate metabolite distribution.

Table 6

Average distribution of folate metabolites in different biological matrices measured in mouse tissue, human whole blood and mouse bone marrow cells.

\begin{tabular}{|c|c|c|c|c|c|c|}
\hline & Muscle $(\mu \mathrm{mol} \backslash g)^{\mathrm{a}}$ & Brain $(\mu \mathrm{mol} \backslash \mathrm{g})^{\mathrm{a}}$ & Liver $(\mu \mathrm{mol} \backslash \mathrm{g})^{\mathrm{a}}$ & Heart $(\mu \mathrm{mol} \backslash \mathrm{g})^{\mathrm{a}}$ & Human blood $(\mu \mathrm{mol} \backslash \mathrm{L})^{\mathrm{a}}$ & Bone marrow cells $(\mu \mathrm{mol} \backslash \mathrm{L})^{\mathrm{a}}$ \\
\hline Folic acid & 0.00018 & 0.00019 & 0.00084 & 0.00022 & $\mathrm{ND}^{\mathrm{b}}$ & $\mathrm{ND}^{\mathrm{b}}$ \\
\hline Tetrahydrofolate & 0.00492 & 0.02311 & 0.46603 & 0.01718 & 0.00233 & 0.00448 \\
\hline 5,10-Methenyl THF & 0.00107 & 0.00025 & 0.00024 & 0.00103 & 0.02634 & 0.07260 \\
\hline 5,10-Methylene THF & 0.00207 & 0.00736 & 0.84642 & 0.00942 & 0.19836 & 0.00343 \\
\hline 5-Formyl THF & 0.00026 & 0.00059 & 0.01054 & 0.00068 & 0.02015 & 0.00074 \\
\hline 5-Methyl THF & 0.00725 & 0.01157 & 0.48178 & 0.01638 & 0.08771 & 0.00736 \\
\hline Dihydrofolate & 0.00100 & 0.00153 & 0.00942 & 0.00128 & $\mathrm{ND}^{\mathrm{b}}$ & $\mathrm{ND}^{\mathrm{b}}$ \\
\hline
\end{tabular}

a Mean value from six independent measurements.

b Could not be determined accurately from whole blood.

the bone marrow cell samples reached $89 \mathrm{nmol} / \mathrm{L}$ with the highest relative content of 5,10-methenyl THF accounting for approximately $80 \%$ of the total folate pool and 5,10-methenyl THF is a precursor for 10-formyl THF derivative. This finding likely results from bone marrow's characteristics as a highly proliferative tissue with an intensive purine synthesis dependent on 10-formyl THF. The average concentrations of the folate metabolites in the respective biological matrices are provided in Table 6 . We also measured the folate metabolites in plasma using the blood extraction protocol. The total folate concentration in the plasma samples reached $1.094 \mathrm{nmol} / \mathrm{L}$, including $0.491 \mathrm{nmol} / \mathrm{L} 5,10$-methenyl THF and $0.604 \mathrm{nmol} / \mathrm{L}$ 5-methyl THF. Such a high concentration of 5,10-methenyl THF was not previously reported, while plasma 5-methyl THF is known as the common circulating form of THF in the body.

\section{Conclusions}

We have developed and validated a rapid, sensitive, precise and accurate method for measuring central folate cycle metabolites in different biological matrices with a wide calibration curve range $(0.5-2500 \mathrm{ng} / \mathrm{mL})$ using liquid chromatography-tandem mass spectrometry. We simultaneously measured seven folate cycle metabolites using a single method with a 5 min run time. Because of the $\mathrm{pH}$ sensitivity of folate cycle metabolites and their interconversions, achieving an accurate quantification for all the metabolites using one method remains challenging. However, we used a single isotope labelled internal standard for all the measured folates achieving an acceptable accuracy. However, we have not used matrix matched calibration curve for calculating concentration values from samples, hence, estimation of absolute values for folate metabolites is not possible with this method. Overall, the validation results demonstrated that the proposed method is reliable and fit-for-purpose for determining metabolites profiles in various metabolomics studies. Furthermore, analysis of various tissue samples can be performed simultaneously using a single protocol that increases the sample throughput and minimises the workload. The developed method can potentially be used in various research fields ranging from nutrition to cancer, and has already been successfully applied to study folate metabolism in mitochondrial diseases [16].

\section{Acknowledgements}

The authors would like to thank Prof. Anu Suomalainen's group for providing the biological samples.

\section{Funding sources}

Biocentre Finland supported this work, while LE was supported by the Academy of Finland. The funding agencies played no role in the study design, data collection, analysis and interpretation of data, nor in the writing of the report or in the decision to submit the article for publication. 


\section{Declaration of interest}

\section{All authors declare no conflicts of interest.}

\section{References}

[1] L.H. Matherly, Z. Hou, Structure and function of the reduced folate carrier: a paradigm of a major facilitator superfamily mammalian nutrient transporter, Vitam. Horm. 79 (2008) 145-184.

[2] J.M. Scott, Folate and vitamin B12, Proc. Nutr. Soc. 58 (1999) 441-448.

[3] V.D. Brouwer, S. Storozhenko, J.C.V.D. Steene, S.M.R. Wille, C.P. Stove, D.V.D. Straeten, W.E. Lambart, Optimisation and validation of a liquid chromatography-tandem mass spectrometry method for folates in rice, J. Chromatogr. A 1215 (2008) 125-132.

[4] A.S. Tibbetts, D.R. Appling, Compartmentalization of Mammalian folate-mediated one-carbon metabolism, Annu. Rev. Nutr. 30 (2010) 57-81.

[5] K.E. Christensen, R.E. Mackenzie, Mitochondrial one-carbon metabolism is adapted to the specific needs of yeast, plants and mammals, BioEssays 28 (2006) 595-605.

[6] N. Pollak, C. Dölle, M. Ziegler, The power to reduce: pyridine nucleotides - small molecules with a multitude of functions, Biochem. J. 402 (2007) 205-218.

[7] J. Fan, J. Ye, J.J. Kamphorst, T. Shlomi, C.B. Thompson, J.D. Rabinowitz, Quantitative flux analysis reveals folate-dependent NADPH production, Nature 510 (2014) 298-302

[8] V.D. Brouwer, G. Zhang, S. Storozhenko, D.V.D. Straeten, W.E. Lambert, pH Stability of individual folates during critical sample preparation steps in prevision of the analysis of plant folates, Phytochem. Anal. 18 (2007) 496-508.

[9] J. Liu, R. Pickford, A.P. Meagher, R.L. Ward, Quantitative analysis of tissue folate using ultra high-performance liquid chromatography tandem mass spectrometry, Anal. Biochem. 411 (2011) 210-217.

[10] E. Odin, Y. Wettergren, G. Carlsson, B. Gustavsson, Determination of reduced folates in tumor and adjacent mucosa of colorectal cancer patients using LC-MS/MS, Biomed. Chromatogr. 27 (2013) 487-495.

[11] C.M. Pfeiffer, Z. Fazili, L. McCoy, M. Zhang, E.W. Gunter, Determination of folate vitamers in human serum by stable-isotope-dilution tandem mass spectrometry and comparison with radioassay and microbiologic assay, Clin. Chem. 50 (2004) $423-432$

[12] Z. Fazili, C.M. Pfeiffer, M. Zhang, R. Jain, Erythrocyte folate extraction and quantitative determination by liquid chromatography-tandem mass spectrometry: comparison of results with microbiologic assay, Clin. Chem. 51 (2005) 2318-2325.

[13] F. Kiekens, J. Van Daele, D. Blancquaert, D. Van Der Straeten, W.E. Lambert, C.P. Stove, A validated ultra-high-performance liquid chromatography-tandem mass spectrometry method for the selective analysis of free and total folate in plasma and red blood cells, J. Chromatogr. A 1398 (2015) 20-28.

[14] European Medicines Agency, Guideline on Bioanalytical Method Validation, EMA, London, 2011.

[15] D.A. Arinbruster, M.D. Tillman, L.M. Hubbs, Limit of detection (LOD)/limit of quantitation (LOQ): comparison of the empirical and the statistical methods exemplified with GC-MS assays of abused Drugs, Clin. Chem. 40 (7) (1994) 1233-1238.

[16] J. Nikkanen, S. Forsström, L. Euro, I. Paetau, R.A. Kohnz, L. Wang, D. Chilov, J. Viinamäki, A. Roivainen, P. Marjamäki, H. Liljenbäck, S. Ahola, J. Buzkova, M. Terzioglu, N.A. Khan, S. Pirnes-Karhu, A. Paetau, T. Lönnqvist, A. Sajantila, P. Isohanni, H. Tyynismaa, D.K. Nomura, B.J. Battersby, V. Velagapudi, C.J. Carroll, A. Suomalainen, Mitochondrial DNA replication defects disturb cellular dNTP pools and remodel one-carbon metabolism, Cell Metab. 23 (2016) 635-648. 